\title{
Fundamental Aspects of High-Temperature Metallurgical Processing
}

\author{
JESSE F. WHITE ${ }^{1,2}$ \\ 1.-Elkem Carbon AS, 4675 Kristiansand, Norway. 2.—e-mail: jesse.white@elkem.no
}

Further technological advancements in pyrometallurgical processing rely on investigations of thermodynamics, kinetics, thermophysical properties, and studies using the powerful tools of scanning electron microscopy and microprobe analysis. This special topic on Fundamental Aspects of High-Temperature Metallurgical Processing is a collection of articles covering a wide array of pyrometallurgical subjects: ilmenite smelting, ironmaking, refractories in ferronickel production, and treatment of secondary materials from tin and copper production.

The first article in this series is a study on the reduction of a titanium-bearing ore, entitled "Effects of Borax on the Reduction of Pre-oxidized Panzhihua Ilmenite" by Yufeng Guo et al. This type of ilmenite contains a large amount of $\mathrm{MgO}$, which makes reduction of titanium more difficult by forming stable pseudobrookite. In this study, fundamental aspects of how addition of borax aids in reduction of pre-oxidized ilmenite were investigated, such as the mineral phase transformation, reduction kinetics, and the mechanism for enhanced reduction.

We then turn to ironmaking with the article "Static Holdup of Liquid Slag in Packed Coke Bed under Oxygen Blast Furnace Ironmaking Conditions" by Guang Wang et al. They contribute with fundamental insights into pulverized coal injection (PCI) in top gas recycling-oxygen blast furnace (TGR-OBF) ironmaking technology. To simulate the lower zone of a blast furnace, they conducted an experimental study of how unburnt pulverized coal particles and introduced ash constituents affect primary slag fluidity and maximum static holdup in the packed coke bed. It was found that an increase in the $\mathrm{Al} / \mathrm{Si}$ ratio in the slag due to incorporation of ash constituents into the slag leads to increased viscosity and greater holdup. An increase in unburnt pulverized coal particles increases the

Jesse F. White is the JOM advisor for the Pyrometallurgy Committee of the TMS Extraction \& Processing Division, and guest editor for the topic Fundamental Aspects of High-Temperature Metallurgical Processing in this issue. apparent viscosity as well. These findings could influence the settings of key operational parameters such as PCI injection rate, coal species selection, and oxygen enrichment.

Next is a fundamental study of chemical corrosion mechanisms of magnesia refractory by liquid slag, entitled "Phase Reactions Between Refractory and High-Acidic Synthetic-CaO-Ferronickel Slag" by Sagadin et al. Synthetic slags comprising the main oxides $\mathrm{SiO}_{2}, \mathrm{MgO}, \mathrm{Fe}_{2} \mathrm{O}_{3}$, and $\mathrm{CaO}$ were melted in a hot-stage microscope on a magnesia substrate, and the phase formation was then analyzed with scanning electron microscopy (SEM)/energy-dispersive x-ray spectroscopy (EDX) measurements. Good agreement was found between the observed phase formation and thermodynamic calculations with FactSage. The improved understanding could help lead to increased refractory lifetime and better refractory performance in ferronickel production.

The next article deals with processing of jamesonite concentrate $\left(\mathrm{Pb}_{4} \mathrm{FeSb}_{6} \mathrm{~S}_{14}\right)$, which is a mineral by-product from the flotation of tin ore. In "Microscopic Study of the Phase Transformation During the Oxygen-Enriched Direct Smelting of Jamesonite Concentrate" by Min Chen and Xi Dai, phase transformations and movement of elements were investigated by analyzing partially oxidized jamesonite particles and crude lead-antimony alloy using SEM and electron probe microanalysis. Such insight could lead to better control of the elements during the smelting process.

We round off the series with an experimental study on partial reduction of copper smelting in "Moderate Dilution of Copper Slag by Natural Gas" by Baojing Zhang et al. Experimental work was carried out to reduce magnetite to fayalite by blowing a stream of natural gas into the liquid slag. $\mathrm{CaO}$ was admixed to reduce the viscosity and promote settling of entrained matte droplets. The results could lead to an alternative industrial treatment process to produce a cleaned slag amenable for further reduction to recover iron units. 
The following papers are published under the topic "Fundamental Aspects of High-Temperature Metallurgical Processing" in the January 2018 issue (vol. 70, no. 1) of JOM and can be accessed via the JOM page at http://link.springer.com/journal/ 11837/70/1/page/1:

- "Effects of Borax on the Reduction of Preoxidized Panzhihua Ilmenite" by Yufeng Guo, Fuqiang Zheng, Tao Jiang, Feng Chen, Shuai Wang, and Guanzhou Qiu.

- "Static Holdup of Liquid Slag in Packed Coke Bed under Oxygen Blast Furnace Ironmaking Conditions" by Guang Wang, Yingli Liu, Zhenfeng Zhou, Jingsong Wang, and Qingguo Xue.
- "Phase Reactions Between Refractory and HighAcidic Synthetic-CaO-Ferronickel Slag" by Christoph Sagadin, Stefan Luidold, Christoph Wagner, Alfred Spanring, and Thomas Kremmer.

- "Microscopic Study of the Phase Transformation During the Oxygen-Enriched Direct Smelting of Jamesonite Concentrate" by Min Chen and Xi Dai.

- "Moderate Dilution of Copper Slag by Natural Gas" by Baojing Zhang, Ting-an Zhang, Liping Niu, Nan-song Liu, Zhihe Dou, and Zhiqiang Li. 